\title{
Embodied Nostalgia
}

by

\section{KIMON KAKETSIS}

\author{
A Thesis \\ presented to \\ Ryerson University \& York University \\ in partial fulfillment of the requirements \\ for the degree of \\ MASTER OF ARTS \\ in the Program of \\ Communication and Culture \\ Toronto, Ontario, Canada, 2011
}

C(Kimon Kaketsis) 2011 


\section{ACKNOWLEDGEMENTS}

Dedicated and in loving memory to my Brother:

SOCRA IES KAKETSIS

Also dedicated to my loving family,

to my Mother and Father:

EFROSENE \& GEORGE KAKETSIS

Thank you for your unconditional love and encouragement, without your support this project would not have been possible.

to my Sisters and my Brothers in law:

Fotiny \& ANGELO SAClamaCiS

ANASTACIA \& MIXALI REPPAS

and their wonderful children:

FotIS \& ALEXIA SACLAMACIS

MichaEL, GEORGE \& ZOE REPPAS

Thank you for all your love, support and advice.

Thank you to my supervisors:

PAUl MOORE \& DON SNYder

Special thank you to:

Ryan Michael Catney, Kasia Chalas, Michelle Horrigan-Foster, Tyler Franch, Jamie Gladstone, Alanna Goldstein, Katherine Huie, Dayna Jones, Alison Powell Kennedy, Erin McCurdy, Jackie Milanov, Inessa Radostin, Milana Lise Saragossi, Scotty Stiles, Colin Smith and Nicola Waugh. 


\begin{abstract}
By looking at the history of snapshot photography from the Kodak Brownie until today's iPhone, the qualities of digital snapshot photography will be measured against its analogue past. Through this critique, I will illustrate how highly valued cultural objects like the photographic print and the family album have been replaced by hypermediated transactions of images stored online via social networking websites. Specifically, I will explore why our contemporary society looks back to its past, and at the same time yearn for the future. Smart-phone developers tap into the niche market of this nostalgic trend and created, for example, the Hipstamatic application to give us images that capture moments that look unique, old, and most importantly, one-of-a-kind. The nostalgic qualities associated with analogue snapshot photography-aged prints, exposure flaws, soft focus, and light leaks-are mimicked by contemporary digital images, creating the illusion of historical uniqueness. Snapshot photography is about memory, time, ritual, and nostalgia; the digital is about hypermediated, immediate and constant social online photo posting. The snapshot photograph finds itself at an interesting point of transition, competing to be one step ahead of the newest technology and at the same time, imitating yesterdays technology by striving to look authentically as if from the past. The new and the old have become intermingled.
\end{abstract}




\section{FOREWORD}

Embodied Nostalgia, as a paper and images that come together to create this book, is an example of what the Communication and Culture Masters Program does best. I was challenged academically, technically and artistically. First and foremost, this book is now an artifact; texture and authenticity, it is a physical object, and will now enter my personal archives to be passed down to future generations as document of me as an academic and as an artist. This project was prompted in response to a current trend in many aspects in photography, for example, contemporary artists reinvestigating found images or family photography to produce new work. Another example is iPhone Camera Applications that mimic analogue processes to produce images that look like the found image or family photograph one would come across in the vintage store or tucked away in a draw. We can't all be exposed to analogue photography because of economic factors and the skill and expertise needed, but digital applications have been able to open things up to the masses, where cost is minimal and no skill is required. Although digital is still out of the economic means of many, there is still a trend that is apparent, and I think collectively, despite economic status, we are uncertain about our futures in a type of modern anxiety, and we all respond to images that remind us of the past, whether found vintage images, iPhone vintage applications, contemporary artists using historical methods to create new work, kitsch commodities such as Lomography. Overall, I wanted to bring awareness to this trend of kitsch or an alternative lifestyle to taking images, and to provide a background to what we are witnessing, highlight the transitions of our photographic habits from analogue to digital and debate what the potential historical consequences might result from this trend.

I started this project with images of my mother when she was young, where I had these personal associations with nostalgia. To me those images of her are perfection, even though they 
are aged, faded and cracked; as an artist I wanted to celebrate that. I used these images and created a new project where I realized it was too personal to balance with my paper that references the masses and domestic photography. I moved from there to found imagery from antique and markets shops, where I had no connection with the people depicted, finding images that I liked aesthetically. Having no personal connection with them I felt that I could manipulate these images to aesthetically make them look rougher around the edges and I produced another body of work. However this time I felt this project was too removed from my interests since it was too much about the materiality of images. Finally, the solution was to take my own pictures and create images that represented the ideas within my paper. The ritual of photographing itself was vital to my personal sense of truth in the execution of the series: purchase of the film; loading my camera; winding and shooting; having the film developed; paying and shuffling through the shots and choosing the right prints almost instantaneously. This process was a holistic experience because the steps in the ritual came together to produce one whole, using outmoded technology with new technology where the parts that came together to equal my project. What became most interesting was that both the lens and the film were contemporary products made to produce images that highlight the unique characteristics of analogue photography. Aside from ritual, I am committed to the technique that I executed to create this project, now that analogue photography is now only associated with its nostalgic characteristics (grain, blur, etc.). I made a body of photographic work that separates itself from the digital photography that mimics analogue characteristics. I produced this project with knowledge craft and skill that goes analogue processes. First, what inherently separates my project is that no digital application can mimic it because the change from emulsion to pixels impels us to rethink fundamentally what photography is. Second, the investment behind that ritual infuses my project 
with emotion and exhibits the process it endured. This clearly articulates the 'human touch' associated with analogue and which lacks in digital photography. Finally the process of trial and error helped me set up the building blocks to make the images to Embodied Nostalgia. I created contemporary images that reflect the issues I laid out within my paper, using a combination of analogue and digital techniques to construct these images that can be interpreted as timeless, classic, or maintain nostalgic qualities. My intention was to convey a sense of contemplation and familiarity where each image tells its own narrative. I wanted the images to be universal and at the same time be symbolic of my idea of nostalgia.

I describe my images as a montage that resembles the aesthetic and visual theory of the moving image, maintaining a form of narrative. The overlapping of the images, lines fading and blurring into other images, is to refer to one roll of film, even though I digitally compiled them, I wanted the narratives to convey as if one was not winding their film completely to get multiple exposures. As my project evolved and grew I realized I had build a structure to my methodology. The each image montage within my book are instants sewn together to create moment. Our moments are lived experiences that we store in our memories. Thus, we keep photographs to act for our memories. I have constructed a diagram to represent my thought process:

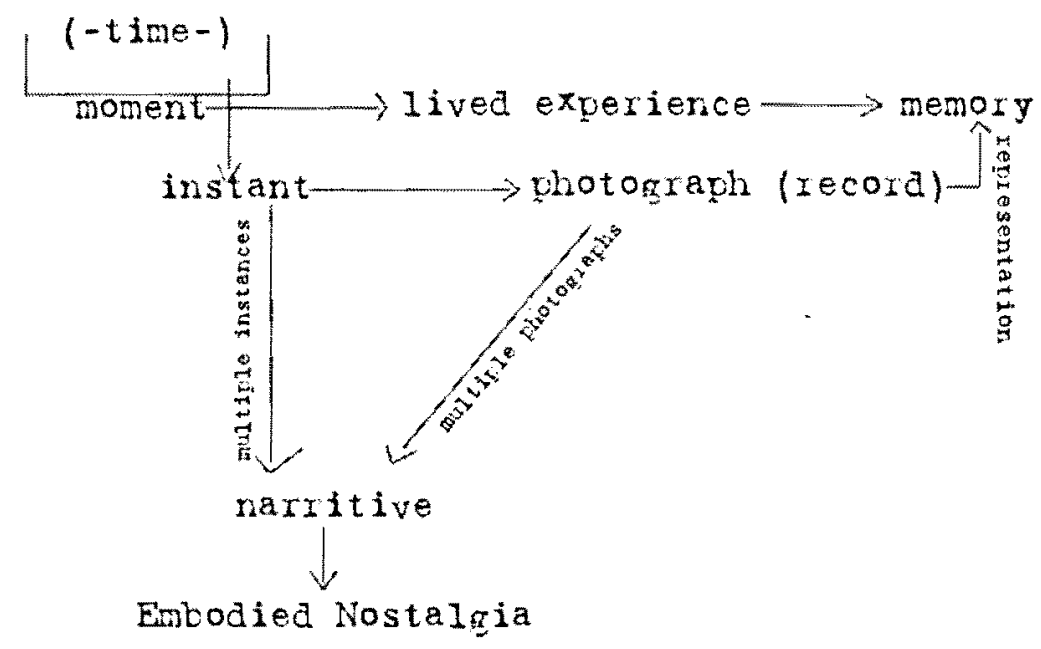


In hindsight, the above diagram merges my artistic and methodical point. Our smartphone cameras allow us to have instant social networking that allows our photo albums to exist everywhere. However this disrupts our representations of memory, our records or photographs have become fleeting and may not survive the future to be called upon to assist our recollections of our memory. Our true legacy is to have an actual document that is material and can enter an archive. It is our right to archive our lives in safe and reliable way, to have our records as physical artifacts that will survive generations from now. Without making analogue archives, I fear that digital images that we have now may become outmoded for the technology of the future. 
In counterpoint to our fascination with cyberspace and the virtual global village, there is a no less global epidemic of nostalgia, an affective yearning for a community with a collective memory, a longing for continuity in a fragmented world. Nostalgia inevitably reappears as a defense mechanism in a time of accelerated rhythms of life and historical upheavals.

Imagine posing for a snapshot at birthday party or on vacation, and the camera has run out of batteries. Or again, the snapshots from that birthday party or vacation are accidentally erased from the camera's memory card. Or, in the not so distant past, the roll of film with those snapshots from the party or trip was exposed and ruined, something not known until the pictures were developed. Was the party itself ruined? Was the vacation not worth it? No wonder we now have equipped ourselves with failsafe digital devices in order to avoid photographic atrocities.

Do we need to photograph experiences to remember what happened? Photographs are used to store our memories, perhaps so much that the camera is an essential part of contemporary experience. Our cellphones are already more camera than phone. Sharing the image is at least as important as the text or voice message. Our digital cameras and phones are record keepers in the palms of our hands. The promise of perfect pictures in an instant has been fulfilled; we have the capacity to instantaneously share them.

Yet, I find myself unsatisfied. Digital snapshot photography seems like a falsification; the digital cameras that create perfect exposures do not seem honest. It seems, however, that many share my sense that the digital image is too good to be true. A photography store recently opened in my neighbourhood but none of its products and services are for digital images. This business sells nostalgia for analogue photography. After perusing the selection of their products, I realized that all the top photography applications on my iPhone mimic analogue processes - the same things for sale in this shop. During 2011 Contact Photography Festival in Toronto, many of the photographers also utilized analogue techniques that gave the illusion of turning back time and 
re-inventing of the past. Many also used antique family or found imagery to create new artworks. In today's context, this return to the past illuminates the existence of modern anxiety with the digital revolution. Susan Murray characterizes the introduction of digital photography as prompting fear of "a loss of texture and authenticity," qualities which are "inherent in old image technologies and missing in the 'cold inhuman perfection' of the digital."' According to Bill Nichols" definition of digital photography, "the chip is pure surface, pure simulation of thought. Its material surface is its meaning, without history, without depth, without aura, affect, or feeling." The medium of digital photography brings speed, confusion in time, lacking linearity, and most importantly does not result in material photographs. With digital photography there is a loss of the materiality of the snapshot. Digital images threaten the status of the photograph as meaningful objects to keep, as representations of memory, leaving a legacy of a lifetime. Journalist A.O. Scott writes about the condition of snapshot photography today as a relentless "engine for the mass production of nostalgia ... a photograph takes up instant residence in the archive." 3 M family photographs are vibrant tangible records that help me visually understand my ancestral roots. My anxiety around digital photography is that I fear that future generations will not have the same privilege.

Photography is a cultural habit. We utilize the camera to document many moments in our walk through life. The popular behaviour and cultural norms of documenting life through images turns photographs into material touchstones of memory; pictures can become more important than actual life experiences. Photographic habit teaches us to incessantly document experiences

\footnotetext{
' Susan Murray, Digital Images, Photo-Sharing, and Our Shifting Notions of Everyday Aesthetics (Journal of Visual Culture 7.2), 2008, 147 - 163.

${ }^{2}$ Bill Nichols, "The Work of Culture in the Age of Cybernetic Systems," Electronic Media and Technoculture, ed. John Thorton Caldwell (New Brunswick, NJ: Rutgers University Press), 2000, 104.

${ }^{3}$ A.O. Scott, "On (Digital) Photography: Sontag, 34 Years Later," The New York Times (2011) accessed May 10, 2011, http:/www.nytimes.com/2011/05/08/magazine/mag08Riff.html?pagewanted=1\&_r=2\&ref=magazine.
} 
in order to make them legitimate. On the other hand, the snapshot provides instant gratification. When picture-takers are happy with the image, their usual behaviour is to upload the image to Facebook immediately, in order to prove where one is or has been. This process of documentation has become a routine social habit. As a consequence, the snapshot camera is perceived as a hybrid extension of the pervasive cell-phone but in fact is an extension of the human arm, because it is rare that a person is left without accessibility to a camera ${ }^{4}$. Further, the innovation of the smartphone gives the end-user instant access to online social networking sites and instant online posting capabilities. The founders of mass consumer photography corporation Kodak promised us: "you press the button, we do the rest,", and this notion is transformed today to allow the picture-taker to do the rest themself. The button is now the entire technological network of wireless devices connected to the Internet cloud. Yet the way we view and engage photographic images has not really changed. According to Scott, echoing Andre Bazin's idea of the myth of total cinema, the "the rise of digital culture has not fundamentally altered the nature of photography but rather fulfilled it. ${ }^{, 6}$ Scott describes a scenario worth quoting at length:

Various household computers have become the descendants and digital approximations of those shoeboxes stuffed with prints brought home in envelopes from defunct camera stores. A squadron of albums marches across a high bedroom bookshelf, though the chronological sequence halts around the turn of the present century. Photographs now live and die on phones and screens, in bits and pixels rather than emulsion on paper. ${ }^{7}$

Our relationship with photographs was once tactile; now our consumption of images has changed to viewing them on a screen, and thus, creating a lifestyle of digital excess. The consumption of photography has changed; we have a sense of nostalgia because we grew up with our parents photographs, recounting their stories and childhood pictures of ourselves, safely put away behind

\footnotetext{
${ }^{4}$ Donna Haraway, "A Cyborg Manifesto: Science, Technology, and Socialist-Feminism in the Late Twentieth Century," in Simians, Cyborgs and Women: The Reinvention of Nature (New York; Routledge, 1991), pp.149-181.

${ }^{5}$ Susan Sontag, On Photography (Penguin, 1979), 53.

${ }^{6}$ Scott, On (Digital) Photography. Andre Bazin, trans. Hugh Gray, What Is Cinema?, Berkeley: University of California Press, 2004.

${ }^{7}$ Scott, On (Digital) Photography.
} 
the acetate sheets of the 'family album.' Can we really rely on digital media as the evidence of our existence? With printed photographs and family albums now diminishing, what are we leaving for future generations? Are we keeping keepsakes? Are we keeping digital archives, or are we losing files as technology progresses, forgetting about them somewhere in some lost folder? Are we really going to have external hard drives stored in our attics for our grandchildren to come across and look back into our history, rather than a trunk or hatbox filled with old photographs and records? In the book The Future of Nostalgia, Svetlana Boym explains, "each new medium affects the relationship between distance and intimacy that is at the core of nostalgic sentiment. ... Issues of time, narrative and making meaning are much less relevant in the Internet model. Computer memory is independent of affect and the vicissitudes of time, politics and history $\ldots$ an equally total amnesia that could occur in a heartbeat with sudden technical failure." ${ }^{\prime 8}$ Acknowledgment and accountability need to be taken, and we need to snap out of this daze of reliance on Facebook to be the safe keeper of our memories and histories. Yet, on some level, we are unsettled, and to alleviate this sense of uneasiness, we are escaping the present with a fixation on the past. This anxiety is alleviated, by harkening back to a time that is safe, simple, original, warm and familiar; we return to a place once known as 'nostalgia.'

The photographs accompanying these words articulate my reaction to this digital revolution even more than this written argument. My intention is to investigate the essence of analogue photography. The photographs provide visual representations of the inherent components of analogue photography referenced throughout this writing. The photographs convey the viewing pleasure of a fading camera culture, and are meant to be timeless, romantic representations of the 'in-between.' These are images of the moments in-between frames of the experience rather than the snapshots that make it to the family album. I am paying homage to the

\footnotetext{
${ }^{8}$ Svetlana Boym, The Future of Nostalgia (New York, NY: Basic Books), 2002, 346 - 347.
} 
forgotten, discarded and awkward snapshots tucked away in our drawers and trunks. Amid the birth of new technologies, our digital culture is witnessing the demise of the print photograph, leading the precarious sense of nostalgia in photography to become redefined and made more complex. The images produced by digital means mimic the same artistry, process, documentary value, and socio-cultural rituals as analogue photography, despite the perceived loss of uniqueness in digital images. I reconstruct snapshot-like moments, while contemplating the past through relationships of land, memory and family. The fleeting moments in the images root themselves in the fragmented pieces that create the photograph. The constructed images do not recreate a specific moment or a specific time and space, but strive to stimulate a subconscious reaction to reminisce about photographs that contain your own history and visual memories. Ultimately my accompanying photographs are intended to reanimate the idea of the past and provide a sense of nostalgia, but thoughtfully. This project is my interpretation of the current trend in the return of analogue photography, where, digital photography is still pervasive but now with an analogue aesthetic. 
The disease of this millennium will be called chronophobia or speedomania, and its treatment will be embarrassingly old-fashioned. Contemporary nostalgia is not so much about the past as about vanishing the present.

Svetlana Boym 351

When we take a photograph, we assume that we capture an image of a moment; however, a photograph is actually a record of an instant of a moment. According to Roland Barthes; a photograph is "a thing," shows us something, but is also a physical object itself. This subjective experience shows us photography's capability of indexing events and objects that have been ${ }^{9}$. The photographs that hold the things that have been, are records of instants but representations of moments. Our moments are lived experiences that we store in our memories, fleeting, non linear and fading. Thus, we keep photographs to act for our memories. My project is a representation of memory and the images symbolizing the awkward, missed and transitory in-between instants that we capture with our cameras. The multiplicity of images and the narrative quality are my interpretation of memory and nostalgia, which are inherent to the essence of photography. The images attempt to signify the instant right before and right after an image is taken, and attempt to defy time by showing us something honest, off-guard, and vulnerable. They are instants sewn together to encapsulate the truth of the moment.

This body of work cultivates and re-imagines the simple everyday snapshot. A photograph has the capacity to conjure strong and vivid memories, places and events. The accompanying artwork is meant to be universal and speak to the common human experience and its relationship to the photograph. My intention is to emphasize that the experience of making photographs blurs the line between experience, invention, and imagination. This series is about truth and fiction, remembrance, and reconstruction, in order to collapse the past and present. My inspiration encourages the memory to recall that of imagery from the past: Kodak advertising,

\footnotetext{
${ }^{9}$ Roland Barthes, Camera Lucida: Reflections on Photography (Hill and Wang, 1994), 6.
} 
personal family photographs and found 'vintage' photographs in antique stores and markets. Today there exists a desire for alternative analogue-looking photos, either kitsch or nostalgic. This project is intended to speak to that desire, and is also intended to act as a representation of analogue techniques and tactility. These images demonstrate the process of hands-on picturemaking. I will reveal the time spent and shards of evidence where it has been, and what the page has physically endured. It is an aesthetic representation; however, it reveals my commitment to the notion of materiality. Finally, this investigation of nostalgia, time and analogue vs. digital intends to enable the viewer to contemplate the outmoded idea of longing, since we wish "to prolong our time, to make it free, to daydream, against all offs resisting external pressures and flickering computer screens." ${ }^{10}$ As digital claims to function with ease, our analogue selves are now more simplistic and familiar.

\footnotetext{
${ }^{10}$ Boym, Future of Nostalgia, XIX.
} 
In the book The Future of Nostalgia, Svetlana Boym defines the term off-modern as the "tradition of critical reflection on the modern condition that incorporates nostalgia." She states that the adverb off "confuses our sense of direction" and "allows us to take a detour from the deterministic narrative of twentieth-century history." Off-modernism, Boym asserts, is the "critique of both the modern fascination with newness and no less modern reinvention of tradition were reflection, longing, estrangement and affection all go together." She explains the off-modernists' "creative rethinking of nostalgia [is] not merely an artistic device but a strategy of survival."11 Using Boym's paradigm, off-modernism is applicable to my artwork. Using this artwork to reflect on the current condition of snapshot photography, in relation to nostalgia, this project is anti-linear and anti-chronological, confusing time and leaving it up to the viewer to interpret narratives. My strategy, as Boym states, is the rethinking of nostalgia: a reexamination of the role of analogue snapshot photography against what it once was and what it is today. Using the production of photographs, I intend to conceptually 'take back' analogue photography and subsequently extract nostalgia. The overlap of snapshot photographs confuses the panoramic direction and creates a "cinematic image of nostalgia. ... [The] double exposure, or a superimposition of two images ... [bring together] home and abroad, past and present, dream and everyday life. The moment we try to force it into a single image, it breaks the frame or burns the surface."12 The intention is for the photographs to communicate to the viewer a sense of loss and bring back the yearning for tactility that is inherent in analogue photography.

Susan Murray states in her essay, Digital Images, Photo-Sharing, and Our Shifting Notions of Everyday Aesthetics that there is a long, "complex history of amateur photography and its relationship to domesticity, leisure, consumerism, and artistic production that is relevant"

\footnotetext{
"This and prior two quotations, Boym, Future of Nostalgia, XVI - XVII.

${ }^{12}$ Boym, Future of Nostalgia, XIII - XIV.
} 
in exploring the important relationship between the consumption of photographs and 'snapshots. ${ }^{13}$ Professional and amateur photography has been explored and discussed in relation to history, memory, absence, and loss. Theorists such as Friedrich A. Kittler, Andre Bazin, Walter Benjamin, Roland Barthes and Susan Sontag "have all made arguments that have consigned the meaning and practice of photography largely to its ability to preserve moments in time." ${ }^{14}$ From the start, the camera's "democratic potential was apparent ... as the photographic profession expanded and diversified, ... so, too, did the range of pleasures available to the amateur. Aesthetic refinement went hand in hand with mass accessibility. Cameras became cheaper, lighter and easier to use."15 In the 1880 s, Kodak gave the masses the agency to take their own photographs in order to capture moments and were the first to introduce modern snapshot photography with the Kodak Brownie. The Brownie was a simple box camera with a fixed-focus lens that came preloaded with film. With the handheld camera people became artists, operators, and archivists. It was a novelty and convenience that they were in control of their pictures and were able to create their own cultural artifacts. Simultaneously, the operator became the photographer and the singular owner of their images. Kodak branded a lifestyle of domestic photography and sold the masses the idea that they would never again lose the opportunity to capture a moment. As Sontag explains, "The sales pitch for the first Kodak, in 1888, was: 'you press the button, we do the rest." ${ }^{\prime 16}$ Kodak's strategic and seductive marketing was successful and prolific, implanting in the collective consciousness that one needed to capture and record each and every one of life's moments. Nancy West, in Kodak and the Lens of Nostalgia, states that the "ads reveal the fantasies and ambitions of modern culture, their ubiquity having granted

\footnotetext{
${ }^{13}$ Susan Murray, Digital Images, Photo-Sharing, and Our Shifting Notions of Everyday Aesthetics (Journal of Visual Culture 7.2), 2008, 151.

${ }^{14}$ Murray, Digital Images, 154.

${ }^{15}$ Scott, On (Digital) Photography.

${ }^{16}$ Sontag, On Photography, 53.
} 
them an unrivaled iconic significance." 17

Kodak made photography a potent force in American culture by targeting amateurs interested in "keeping a personal record of their everyday life, objects, places, of people that interest them."18 Jay D. Bolter and Richard Grusin in their book Remediation: Understanding New Media, define photography as an "automatic process [that] is mechanical and chemical,"19 could be used by all enthusiasts, amateurs and hobbyists in every common household. They continue to define the mechanics: "[t]he shutter opens, and light streams through the lens and is focused on a chemical film. The process of recording itself is holistic, with no clearly defined parts or steps. ${ }^{, 20}$ When the roll was finished, the entire apparatus was sent back to the Kodak factory in Rochester, N.Y., where the pictures were developed into pictures, camera was reloaded, and returned the newly-loaded camera and processed photographs to the customer. ${ }^{21}$ The purchaser was guaranteed that the picture would be "without any mistake." ${ }^{, 2}$ Susan Sontag in her influential book On Photography explains, "in the fairy tale of photography the magic box ensures veracity and banishes error, compensates for inexperience and rewards the innocence."23 From these exposures of moments in time came the incredible printed images that were collected by the masses and placed in albums for viewing, acting as objects for conversation and recollection. Martin Lister in his essay Extracts from Introduction of the Photographic Image in Digital Culture defines still images "in the domestic world [as] an occasion for talk,

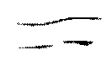

\footnotetext{
${ }^{17}$ Nancy West, Kodak and the Lens of Nostalgia (University of Virginia Press), 2000, XI.

${ }^{18}$ West, Kodak and the Lens of Nostalgia, 40.

${ }^{19}$ Jay D. Bolter and Richard Grusin, Remediation: Understanding New Media (MIT Press), 2002, 27.

${ }^{20}$ Bolter and Grusin, Remediation, 27.

${ }^{21}$ Mia Fineman, "Say Cheese! A history of the American snapshot," Slate, accessed July 10, 2010, http://www.slate.com/id/2175969.

${ }^{22}$ Sontag, On Photography, 53.

${ }^{23}$ Sontag, On Photography, 53.
} 
reminiscence and commentary. ${ }^{24}$ According to Sarah Kember in her essay The Shadow of the Object - Photography and Realism, photography for amateurs was "a cheap and efficient means of promoting secular-sacred objects for mass consumption."2s

The Kodak system offered an efficient, economic, and accessible way to allow anyone to use the medium in creative ways. This 'democratic' photograph resulted in collages and clusters on pages of family albums that incorporated innumerable black-and-white snapshots, combining portraits, travel snaps, and street scenes. ${ }^{26}$ According to Kember, Sontag theorizes that photography "'is mainly a social rite, a defense against anxiety, and a tool of power.' Family photographs 'restate symbolically, the imperiled continuity and vanishing extendedness of family life,' and tourist photographs 'help people to take possession of space in which they are insecure." They are not only forms of power-knowledge but also reactions of fear." ${ }^{27}$ Snapshot photographs, therefore, settle our anxiety by assuring that we never lose a fleeting moment or memory. Through recording, we are securing our presence in the physical world. Gillian Rose writes in Doing Family Photography: the Domestic, the Public and the Politics of Sentiment that the act of taking snapshots became "indexical: [photographs are] dated, stored, displayed, looked at and circulated - and disposed of only rarely. ${ }^{28}$ Everyday images, according to Susan Murray are "the types of images that we can create or engage with on a regular basis that evoke or reference the more ordinary or frequent moments of our lives."29

Here I will provide a brief historical review of photography from the Kodak up to present

\footnotetext{
${ }^{24}$ Martin Lister, "Extracts from Introduction of the Photographic Image in Digital Culture," The Photography Reader, ed. Liz Wells (New York: Routledge), 2003, 222.

${ }^{25}$ Sarah Kember, "The Shadow of the Object - Photography and Realism," The Photography Reader, ed. Liz Wells (New York: Routledge), 2003, 203.

${ }^{26}$ Fineman, Say Cheese.

${ }^{27}$ Kember, The Shadow of the Object, 210.

${ }^{28}$ Gillian Rose, Doing Family Photography: the Domestic, the Public and the Politics of Sentiment (London, GB: TJ International Ltd), $2010,41$.

${ }^{29}$ Murray, Digital Images, 151.
} 
day and compare it against iPhone photography. Since today's trend is to capture images in order to legitimize moments, by documenting rather than experiencing, I believe we are currently experiencing a Second Wave of commodified snapshot culture, that I define as the "automatic," and redefined circulation of archiving of domestic images. As Murray states, this has been brought on by "the confluence of digital image technology along with social network software. ${ }^{30}$ It was easy then, and it is even easier now, again, like Kodak advertised, to just "press the button." As traditional media, such as photography, age they enter perilous terrain and need to evolve or risk extinction. When television was introduced, it was believed it would bring the extinction of cinema and radio. Today, the smartphone can be seen as a threat to traditional snapshot photography. The fact that both television and radio have survived corroborates the hypothesis that evolution, not extinction has occurred. This is the primary rule of media ecology, and we are currently witnessing the peak of transition with snapshot photography.

As the 'art' of snapshot photography evolves, vis-à-vis smartphone technology, digital point-and-shoot apparatus' become increasingly threatened with extinction. Because photographic film has been displaced by easier digital innovations, people are taking more pictures than ever. This is because smart-phones have further democratized the medium; everyone can now participate in taking unique photographs. The iPhone is portable, easy, and most importantly instant, which gives the end-user a significant advantage in social networking realms - you can post images as things happen. Your photo album is instant and exists everywhere.

We are accustomed to seeing and having photographs around us constantly and we constantly take pictures ourselves; "we are immersed in photography so much that we are not aware they are around us: habit hides them [and the] habitual is redundant ... thus we are

\footnotetext{
${ }^{30}$ Murray, Digital Images, 156.
} 
surrounded by redundant photographs [and] one redundant photograph replaces another" (in newspapers, shop windows, online, etc.). ${ }^{31}$ The challenge to a photographer, then, is how to "oppose the flood of redundant photographs" aesthetic - whether present in digital photography, the internet, television, or in the life of the city streets - is fleeting, malleable, immediate, and contains a type of liveness in its initial appearance that is lost once it is placed under glass or replaced by an even more recent image." The social network has become so prolific in contributing to creating our identities that without the constant update of daily occurrences, no matter how mundane, our existence is not legitimate, and thus we do not exist. On these social networking websites, photography is "less about the special or rarefied moments of domestic/family living (for such things as holidays, gatherings, baby photos) and more about an immediate, rather fleeting display of one's discovery of the small and mundane.,33

The smartphone embodies the utopian ideal because it has combined innumerable technologies into one handheld device. These technologies empower us to construct and disseminate our identities, as well as facilitate the consumption of others' identities, giving us complete control and a sense of security in the palm of our hands. By appropriating other media and combining them into a new technology (camera, phone, book, personal computer), the older media thereby become obsolete. They do not become obsolete because they are no longer functional, but rather are pushed aside by newer technologies that improve on the properties of the older ones. To clarify: older media does not die, it simply gives way to newer technologies that appropriate their qualities. Michelle Henning states in her essay New Lamps for Old: Photography, Obsolescence, and Social Change: "[y]esterday's new thing does not simply

\footnotetext{
${ }^{31}$ Vilém Flusser, Towards a Philosophy of Photography (Reaktion Books), 2000, 29.

${ }^{32}$ Flusser, Philosophy of Photography, 29.

${ }^{33}$ This and prior quotation, Murray, Digital Images, 151 - 157.
} 
disappear, nor does it just get refashioned by new technical process or as new media content. Instead it continues to exist at the margins of culture. ${ }^{34}$ The iPhone delivered what Kodak promised, instant digital pictures with the press of a button, immediately available to share and consume online via various social networks helping to settle our anxiety to never lose a moment, by consecrating experience in imagery, consumed in the public domain.

Personal archiving is collecting the cherished artifacts that recount our existence throughout the years, such as photography albums, keepsake boxes, personal memorabilia, etc. Personal "photography is a record of your living"35. Since digital photography has come to the forefront the act of recording our living hasn't ceased, quite the opposite, we are recording our existence more than ever, continually updating our day-to-day digitally. However, what has begun to cease is the physical evidence of our lives, that being print photographs. We find the diminishing 'family album' leaving only digital fingerprints of our memories and experiences. Andre Bazin (1967) in his book What is Cinema? has made similar claims, arguing, for example, that in family albums, "the gray or sepia shadows, phantomlike and almost undecipherable, are no longer traditional family portraits but rather the presence of lives halted at a set moment in their duration ... for photography does not create eternity, as art does, it embalms time, rescuing it simply from its proper corruption. (p. 14)"36. This choice in recording and saving our histories may either leave nothing for the future to be nostalgic about or leave nothing at all.

Before online social networking and emailing, the primary way of viewing photographs was flipping through photographic albums, page by page, or through a stack of the familiar $4 x 6$ photographs, feeling the prints between your fingers and thumbs. This has evolved online. In

\footnotetext{
${ }^{34}$ Michelle Henning, "New Lamps for Old: Photography, Obsolescence, and Social Change," Residual Media, ed. Charles R. Acland (Minneapolis: University of Minnesota Press), 2007, 53.

${ }^{35}$ Paul Strand in On Photography, 183.

${ }^{36}$ Murray, Digital Images, 154.
} 
browsing Flickr, for example, "one is invited to explore thousands of images organized not only through technological features, such as tags, groups, and batches, but also through the less concrete processes and functions of fetishization, collection, memory, flow, taste, signification, and social networks. ${ }^{, 37}$ As our relationship with computers has become highly intimate, constantly being online and connected, the relationship to our and other people's personal images has become less intimate due to the experience of viewing images on the computer screen. A computer screen, in other words, is a window or portal to only the digital realm, rather than image in itself. In her book The Virtual Window: from Alberti to Microsoft Anne Friedberg explains that: "computing devices added a screen for the display of data, the graphical user interface (GUI) introduced an entirely new visual system - a text or image in one 'window' meets 'other texts or images in other 'windows; on the same screen. Above, below, ahead, and behind are simultaneous on the computer display, where each element in composition is seen separately with no systematic spatial relationship between them." 38 The act of consuming photographs on a screen has changed our relationship to images. Friedberg further explains that:

An early component of the graphical user interface, the computer "window" referred not to the full expanse of the computer screen, but rather to a subset of its screen surface: an inset screen with the screen of the computer, one of many nested on its "desktop" The computer "window" shifts its metaphoric hold from the singular frame of perspective to the multiplicity of windows within windows, frames within frames, screens within screens" ${ }^{\text {"39 }}$

This multiplicity of 'windows' that contain the photographs we view causes our perception of images to be extremely fleeting and disrupts the linear narrative of consuming images. Friedberg explains that " $[t]$ he vernacular 'space' of the computer screen has more in common with surfaces of cubism - frontality, suppression of depth, overlapping layers ... [remaking the] visual vernacular [a] fractured, multiple, simultaneous, time-shiftable sense of time and space." ${ }^{, 40}$

\footnotetext{
${ }^{37}$ Murray, Digital Images, 149.

${ }^{38}$ Anne Friedberg, The Virtual Window: from Alberti to Microsoft (The MIT Press), 2006, 2.

${ }^{39}$ Friedberg, The Virtual Window, 2.

${ }^{40}$ Friedberg, The Virtual Window, 3.
} 
Therefore, these online transactions disrupt our sense of time and space, as we are no longer telling our stories through our photography in a linear fashion. Susan Murray supports this by arguing, "that the social use of digital photography, as represented on Flickr, signals a shift in the engagement with the everyday image that has to do with a move towards transience," causing a collective imagination of the past because pictures have come to erase the events we have experienced. This non-linearity collapses our past and present into a bundled online 'cloud.' Murray supports this as she argues that this social practice signals

a definitive shift in our temporal relationship with the everyday image, and have helped alter the way that we construct narratives about ourselves and the world around us [creating a] ... historical continuity and discontinuity. The digital image tears apart the net of semiotic codes, modes of display, and patterns of spectatorship in modern visual culture - and, at the same time, weaves this net even stronger. The digital image annihilates photography while solidifying, glorifying and immortalizing the photographic ${ }^{41}$.

The act of viewing images in jumbled formation on a screen eliminates intimacy, the experience is reduced to illuminated pixels that make up the image, and our impulse in front of a computer is to keep 'surfing.' The time spent with a digital image on the screen is quick and impersonalcreating a definite loss in our relationship to photography. Lev Manovich stated it best in his essay The Paradoxes of Digital Photography as we are now experiencing "photography after photography., ${ }^{42}$

Social networking websites are virtual spaces where individuals use a forum to create and control their identities. They manage what people see and ultimately influence how others perceive them. Images that are stored and displayed online establish our identities and legitimize our existence. The best example of one such website is Flickr. Susan Murrayexplains:

On Flickr, each member's page is part of a decentralized network of similar pages, and contributes to the construction of a community and a larger collection of photographs. ... Flickr has become a collaborative experience: a shared display of memory, taste, history, signifiers of identity, collection, daily life and judgment through which amateur and professional photographers collectively articulate a novel, digitized (and decentralized) aesthetics of the everyday. Flickr has become so popular, and the images it contains so well

\footnotetext{
${ }^{41}$ This and prior quotation, Murray, Digital Images, $151-153$.

${ }^{42}$ Lev Manovich, The Paradoxes of Digital Photography, accessed June 22, 2011 , http://www.manovich.net/TEXT/digital_photo.html.
} 
distributed and displayed, that it has become one of the most active social networks around. It is also one of the rare sites centered more on image than on text. ${ }^{43}$

The immense popularity of contemporary social networking activity, and the confluence of imagery found on social networking sites, points to its dominance within the cyber world. Essentially, social networking websites are used as personal archives for our digital photography, where images are stored, shared and disseminated.

Photography is the ultimate record-keeping device; Susan Sontag states that it inherently democratizes "all experiences by translating them into images. ${ }^{, 44}$ We can prove that we have visited a destination, attended an event or celebrated a moment in time. Nancy West in Kodak and the Lens of Nostalgia perfectly supports this by stating: "[p]erhaps more than ever before, we depend on photography not only to enrich but to 'certify' our experience, according to Sontag, who ... argues 'it hardly matters what activities are photographed so long as photographs get taken and cherished' (8). ${ }^{, 45}$ Due to this same online social networking, our sense of identity is in crisis because it creates a sense of loss. The consumption of photography has changed from shuffling through photographs and handling albums, to viewing images on a computer screen. The experience has changed our relationship with viewing photographs. As online images are not tactile, their existence online is quickly discarded. Murray explains: "In everyday digital photography, there is ... an implicit acknowledgement of the inability of photos to hold onto certain moments. Rather than interpret this as a type of death, in the display of digital photography in social network sites there is an already accepted temporariness to one's sense of publicly presented self in all of life." This creates the incessant need to upload and post, to constantly build our identities in order to continually prove that we exist and are living. In other

\footnotetext{
${ }^{43}$ Murray, Digital lmages, 149.

${ }^{44}$ Sontag, On Photography, 7.

${ }^{45}$ West, Kodak and the Lens of Nostalgia, XI.
} 
words, images need to be 'real time' in order to be acknowledged. In this way, according to Murray, "photography is no longer just the embalmer of time that Andre Bazin (1967: 14) once spoke of, but rather a more alive, immediate, and often transitory, practice/form. ${ }^{, 46}$

Analogue photography did not want to go - it was exiled. With the advances of technology, a new 'way of life' came in offering something so lucrative and easy, an alternative process perhaps whose secret mission sought the demise of analogue processes. Analogue photography now seems to be a refugee rescued by artists and people who practice 'alternative' photography otherwise known as Lomography. Conversely, the technological evolution to digital photography caused a lack of human physical investment that made snapshot photographs more stagnant, boring and emotionless. The "fad for lo-fi cameras, ... 'point-and-shoot' compact camera with a glass lens ... [are mainly] adopted by artists and photographers who [are] attracted to the ... effects [it] produce[s]. ... [T] he product is marketed in terms of an 'attitude.",47 Corporations that create photographic lifestyle brands like Lomography ${ }^{48}$ incorporate this as part of their marketing strategy - "Lomography is not an interference in your life, but part of it" and effectively package the idea of nostalgia in order to successfully sell an alternative kitsch lifestyle. As digital processes become the mainstream practice in photography, the aesthetics of toy camera pictures, the Diana or Holga for example, become increasingly linked to an alternative kitsch form. The success of this venture comes from the idea of selling analogue photography as a lifestyle product, something ingrained in popular culture, that in turn is packaged and sold as a lifestyle. We can therefore characterize the reemérgence of film as a popular cultural phenomenon that embraces nostalgia. We create nostalgia as a collective

\footnotetext{
${ }^{46}$ This and prior quotation, Murray, Digital Images, $151-156$.

${ }^{47}$ Henning, New Lamps for Old, $56-57$.

${ }^{48} \mathrm{lo}$-fi cameras, http://www.lomography.com/.

${ }^{49}$ www.lomography.com
} 
idealized past in which analogue photographic processes are the norm. In other words, analogue photography is now only associated with its nostalgic characteristics. such as faded prints, blur and grain. As Kember explains, in addition "to romanticism (extreme or not) about the past, photography offers instant romanticism about the present." demonstrated by the re-emergence of film has a bittersweet yearning for a past generation that is romanticized in old photographic prints.

Playing with analogue photography instantly opens one up to an entirely new world of creativity. Filmic toy and lomographic cameras embody the inherent 'essence' of film, or in other words they provide the nostalgic characteristics that popular culture yearns for. This community interested in the analogue technique embraces the qualities and processes that cannot be fully duplicated within digital photography and software. Snapshot photography finds itself at an interesting cultural moment at crossroads with digital applications. Smartphone apparatuses have picked up on the desire for meaningful snapshots with increasing speed and have created a market similar to that associated with the Lomography lifestyle. The application developers for snapshot smartphone cameras have eerily achieved a convincing artificial clone where digital images mimic analogue photography. There are applications that replicate faded vintage prints, fish-eye, super grain, lomo, quad-cam, and so on. The abundance of these applications created to manufacture the aesthetic of nostalgia and produce the realism of analogue fail to deliver the satisfaction of the ritual. The ritual of the thought and development process of film is the essence of photography that is lost.

The ritual to analogue photography required investment, process, and awareness. The average roll of film is 24 frame shots, compared to the digital camera with limitless shots; one had to be conscious of shooting analogue. The value behind analogue photography is choice,

\footnotetext{
${ }^{50}$ Sontag, On Photography, 67.
} 
process, product, and sentiment. In the case of the digital shooter, however, one can take repetitive, automatic and unconscious photos of even the most mundane until satisfied. Again the analogue ritual takes in the situation, access it, no matter how quickly, and deem it worthy of document. One invests emotion, and therein lies the value. Value now is displaced online by the act of online social exchange. A picture that sits in a drawer for decades is tangible and exists, however, I must argue here, a digital file does not exist, it is not tangible. Allowing our prints to age contributes to our legacy and histories, we will not become subjects in a photograph that will become an "object of rueful feelings, because [the photograph] has aged or decayed," wit without making analogue archives, we will leave nothing for future museums and archives.

${ }^{51}$ Sontag, On Photography, 15. 
In December 2009, iPhone introduced the Hipstamatic, a photo application that recreates the experience of using a Lomographic camera, a toy plastic camera used for quick and instant exposures. The Hipstamatic is a digital version of the toy camera for a new generation of people that love to capture moments and want them to look like unique, old photographs. The images that this application produces mimic square 120 film prints, with rough edges, fading, light leaks, and blurry patches to create an image that appears to be from another time. Exhibiting these images on online forums (Facebook, Flickr, etc) communicates to viewers that these photo-takers lead the desired 'alternative' lifestyle, part of which involves being interested in the aesthetics of older photographic processes. This application "brings back the look, feel, unpredictable beauty, and fun of plastic toy cameras from the past. ${ }^{, 52}$ It produces images that look like aged or vintage prints and render an 'authentic' wear and tear look. Digital photography, since its conception has been trying to mimic analogue photography; this application copies analogue terminology, there is no physical or technical reason for this. Essentially, the iPhone does not resemble a traditional camera; the screen of the iPhone resembles a plastic toy camera. Upon launching the program, during loading, there is a message that says: "please wait, wiping off lens." This gives the illusion of the physical ritual one would take with an analogue camera. The application is also interactive, where the user can switch lenses, change roll of film and is equipped with 'flash' and 'shutter' noises. The appearance and audio are familiar with traditional analogue cameras, which

52 "iTunes," Hipstamatic by synthetic corporation, retrieved from: $\mathrm{http}$ ://itunes.apple.com/us/app/hipstamatic/id342115564?mt=8\&ign-mpt=u0\%3D2.

In the iTunes online store, this application is offered as such:

Digital photography never looked so analog. The Hipstamatic brings back the look, feel, unpredictable beauty, and fun of plastic toy cameras of the past! The Hipstamatic keeps the quirks of shooting old school but gives you the ability to swap lenses, film and flash setting all with the swipe of a finger. Characterized by vignettes, blurring, over saturation, discolored images, Hipstaprints have a casual and seemingly accidental snapshot feel. ... Pictures taken with the Hipstamatic have their very own look and unique character. Artistic and painted with light and quirk, Hipstamatic images are sometimes surprising and offer delicate beauty turning any iPhone into an instant art making machine. Images can be uploaded directly to Facebook, Flickr, or emailed to your friends and family. 
serves no real function other than novelty. Thus, the Hipstamatic application and shooting with the iPhone does not recreate the actual experience of shooting analogue, and in turn questions the authenticity as mere visual representation. This is demonstrated when Henning calls upon Bolter and Grusin to explain this as remediation: ${ }^{53}$ "how digital photography reproduces the formal characteristics and content of chemical photography. Digital cameras mimic aspects of film photography that really have nothing to do with digital photography." Thus, the nostalgic qualities associated with analogue snapshot photography - aged prints, exposure flaws, soft focus, and evidence of light leaks - are mimicked by contemporary digital images, creating the illusion of historical uniqueness. For example, "such as ASA/ISO setting - 'film speed' settings, even though they use no film, and ... they are increasingly built to resemble traditional cameras ... These reproductions are 'mere facsimiles' of the obsolete." ${ }^{54}$ Unfortunately, while these images replicate the hand-made quality of old images this is one of effect, not process. Digitally altered images via smartphone camera applications effectively succeed in recapturing the 'look' of the past; $;^{55}$ however, there is no thrill of possession because there is no physical object to hold

\footnotetext{
${ }^{53}$ Another definition offered by Jay David Bolter and Richard Grusin is remediation as "the formal logic by which new media refashion prior media forms. Along with immediacy and hypermediacy, remediation is one of the three traits of genealogy of new media, (273)."

${ }^{54}$ This and prior two quotations, Henning, New Lamps for Old, $49-56$.

Following Henning $(50-51)$ here:

Photography, then, may be considered not so much a medium as social practice that makes use of a range of different materials and means. This suggests that remediation should be considered in terms of changes in social relations and in the manipulation of physical "stuff" rather than as a property of tendency of new digital media ... Until digital photography, all photography used photosensitive emulsion that allows the image to be stored on the same material the light has hit, so storage and capture occur at the same moment, on the same material. In the most common process this forms the negative, from which multiple positive copies can be made. Photography is thus characterized but its reproducibility and its ability to preserve a likeness, but also, and importantly, be its direct relationship with nature of the real.

${ }^{55}$ We hold close to technology, but fear it unless it is familiar, Roy Furchgott a journalist from The New York Times explains "some people prefer their next new thing to look like an old thing," making us question what is exactly the appeal of the latest electronics that are wrapped in a retro designs.* This familiarity comes from the nostalgic mask technology covers itself with. "[T]he throwback designs make challenging technology seem familiar. For the technically proficient, an old phone handset that connects to a cell phone seems comically ironic. Retro designs can also give a sense of permanence to disposable devices. Some of it is art." $\dagger$

*Roy Furchgott, "High-Tech Electronics Dressed Up to Look Old," NY Times, Technology. The New York Times (2010), accessed March 212011 , http:/www.nytimes.com/2010/12/23/technology/personaltech/23basics.html?_r=1. †Furchgott, Dressed Up to Look.
} 
and contemplate. "We now find ourselves looking at traditional photographs with a nostalgia for the time when digital technology did not exist and could not therefore intervene between the viewer and his desire. ${ }^{, 56}$ Now we find that there are hardly any more $4 \times 6$ images being printed, only images sent straight to online viewing. The re-creation of these nostalgic styles by iPhone applications remind us of the physicality of prints with the distress and aging that is digitally manipulated on the images.

In Throwaways: Work Culture and Consumer Education, Evan Watkins explains "[t]here's every reason dominant ideological productions work very hard to endlessly construct itineraries of the obsolete as survival narratives, to flood so called mass culture with nostalgic reproductions of a fading past - because obsolescence when reproduced as nostalgic object is no longer dangerous. ${ }^{, 57}$ Digital technologies have a sterilizing effect on photography, and, as the aforementioned writer asserts, especially on the political and social associations with which analogue photography's reigning era are associated. If we can accept that the digital file of an image can be considered the "original" (rather than the "negative"), and that it can be reproduced to infinity without effort, cost or inconvenience, the consequence, I argue, is that eventually photographs will no longer be embedded with personal associations and investments. Because an image exists as multiple files, a false sense of security is accomplished that furthers their perpetual intangibility. The fact that personal photographs will not physically age, the same sense of nostalgia will no longer exist for future generations to experience. Certainly, digital snapshot shooting is accessible, but it comes with a loss. The smartphone culture has fulfilled the Kodak prophecy: 'hit the shutter and we do the rest.' The hypermediated snap shot culture with the built-in basic camera on the iPhone does this simply. If an iPhone user is keen on

\footnotetext{
${ }^{56}$ Jay D. Bolter and Richard Grusin, Remediation, 112.

${ }^{57}$ Evan Watkins, Throwaways: Work Culture and Consumer Education (Stanford University Press), 1993, 39.
} 
photography, there is a plethora of applications to choose from and download. These applications simply fuel the fire of digitally manipulated imagery. The sterilization, in turn, creates a newfound uniformity among photographic aesthetics, which then sparks a desire for more 'personalization' in snapshot photography. If we accept these assertions, we can see how it is that our digital pictures are now stagnant, boring, and without emotion. With traditional Kodak cameras, for example, there was the role of the human touch, there was room for error, there were "happy mistakes", there was investment in personal snapshot photography. Currently, with the surgical and sanitary character of digital snapshot photography, there is no allure and it has forgotten its roots.

Susan Sontag explains the nostalgic draw of photographs in her seminal essay On Photography: "photographs are, of course, artifacts. But their appeal is that they also seem, in a world littered with photographic relics, to have the status of found objects." Sontag is clearly pointing out the allure of physical prints that each is a unique one-of-a-kind object. Also, as Sontag further explains, photography has "like mainstream surrealist taste itself - evinced an inveterate fondness for trash, eyesores, rejects, peeling surfaces, odd stuff, kitsch." Overall, "photographs... [are] aesthetically indestructible... photographs, when they get scrofulous, tarnished, stained, cracked, faded still look good; do often look better. ${ }^{, 58}$ The definition that Sontag has laid out is what I firmly believe to be the recipe to entice consumers to the iPhone applications. They render digital pictures with the analogue aesthetic to give us the simulation of having found images that reminds us of the past. ${ }^{59}$ Therefore, the Hipstamatic application can be

\footnotetext{
${ }^{58}$ This and prior two quotations, Sontag, On Photography, 69-79.

${ }^{59}$ The smartphone culture is left wanting more for the snap shot image, hence the desire for alternative photographic applications. As Boym explains: "cyberspace makes the bric-a-brac nostalgia available in digital form, appearing more desirable than the real artifacts"*. In order to set apart from the "normal' digital photographs is to produce vintage looking digital images. However, the act of taking digital photographs remains the same: quick snapshots, easily erasable and re-recordable. While the aesthetic of nostalgia and uniqueness is formulated through stylized applications of the kind I have described, the actual process of uniqueness-creation that took place in analogue
} 
stated successful because is has convincingly replicated the experience of taking analogue photography; it is the experience of taking pictures, that allure users to use this application. I feel that the use of digital mimicking analogue is displacing the present and will confuse the past and encourage the future to come quicker. This temporal collapse will confuse the future that will perhaps one day want to look back to the past. As Boym states: "The history of nostalgia might allow us to look back at modern history not solely searching for newness and technological progress but for unrealized possibilities, unpredictable turns and crossroads." ${ }^{60}$ This leaves me to ask, what is the point of creating images to be nostalgic for now?

\footnotetext{
photography is still unreachable in the realm of the digital. An image created with the iPhone Hipstamatic application "does not reinvent a picture of the past ... rather, [it reinvents] the feel and shape of characteristics [of] objects of an older period" $\dagger$. But does this enact a depreciation of the past? The digital image can be a thousand generations away from the original and indistinguishable in quality from any one of it predecessors: "... technical images [are absorbing] all history [to] create an eternally circulat[ing] memory of man kind" $\$$. The photographic document reclaims people, objects and places from the past while photography borrows from itself. John Storey explains in his paper, Cultural Theory and Popular Culture that "nostalgia ... works in one and/or two ways: it recaptures and represents the atmosphere and stylistic features of the past; and it recaptures and represents certain styles of viewing the past"**. The iPhone Hipsiamatic can therefore be seen to cannibalize the styles of past photography and create a form of 'fake realism' that plays with random stylistic allusions $\dagger \dagger$.

*Boym, Future of Nostalgia, 347.

† Fredric Jameson, "Postmodernism and Consumer Society," Postmodernism and its Discontents, accessed July 8, 2010,116 ,

http://www19.homepage.villanova.edu/silvia.nagyzekmi/cultural/postmodern $\% 20$ consumer.pdf.

$\$$ Lev Manovich, The Language of New Media (The MIT Press), 2002, 242.

\$ Flusser, Philosophy of Photography, 10.

** John Storey, Cultural Theory and Popular Culture (Essex: Pearson Education Limited), 2001, 159.

†† Storey, Cultural Theory, 159.

${ }^{60}$ Boym, Future of Nostalgia, XVI.
} 
It is a nostalgic time right now, and photographs actively promote nostalgia.

Susan Sontag 15

The concept of nostalgia will be contextualized with the current trends of photographic applications that mimic analogue processes. "Nostalgia (from nostos - return home, and algia longing) is a longing for a home that no longer exists or has never existed. Nostalgia is a sentiment of loss and displacement, but it is also a romance with one's own fantasy." This definition today has been idealized, creating the current pervasive culture of style. The iPhone, with its potential for customization and personalization, responds to this demand. The iPhone Hipstamatic application plays on the concept of nostalgia: "[n]ostalgic reconstructions are based on mimicry; the past is remade in the image of the present or a desired future, collective designs are made to resemble personal aspiration and vice versa., ${ }^{, 61}$ Alison Nordström in her essay Dreaming in Color: America and the Kodak Colorama compares the idea of the desire of nostalgia to Kodak, as it also "served to manifest and visualize values that even then were seen as nostalgic, fading, and in jeopardy, salvageable only through the time defying alchemy of [their] cameras and film. ${ }^{, 62}$ The Hipstamatic communicates the same thing: it is provocative because it incorporates the concept of nostalgia. "Nostalgic reproductions could be commodities ... or fake recreations of 'obsolete' groups." ${ }^{, 63}$ Storey states that nostalgic photography "sets out to recapture the atmosphere and stylistic peculiarities" of the past. The recent past for us remains a "privileged lost object of desire," folds back into itself." ${ }^{35}$ There is a sense of homage and re-appropriation as it looks back at its own history and borrows from itself. The image, once an oddity and a marvet, is now so familiar

\footnotetext{
${ }^{61}$ This and prior quotation, Boym, Future of Nostalgia, XIII-354.

${ }^{62}$ Alison Nordström, Dreaming in Color: America and the Kodak Colorama, Rochester, NY: George Eastman House, $2010,4$.

${ }^{63}$ Henning, New Lamps for Old, 56.

${ }^{64}$ Storey, Cultural Theory, 159.

${ }^{65}$ Sontag, On Photography, 51.
} 
and harmless that we are numbed by this overload of images.

I must echo Anna Everette in her essay, Click This: From Analog Dreams to Digital Realities when she states, "It is in the interstices between our nostalgic analogue dreams and discomfiting digital realities that I find productive ideas worth pondering at this pivotal moment in our congealing technocracy. ${ }^{, 66}$ One can find a significant amount of photography applications on the iPhone that mimic not only analogue photography, but the practices that go along with it, from dark rooms to writing on the white frame of a Polaroid. As Everette states:

Perhaps the most surprising development in our ascendant digital new mediascape is the phenomenal and unanticipated success of the reinvented telephone, as a result of its convergence with cellular mobile technologies and wireless services that provide global positioning systems, e-mail and text messaging, Internet surfing, built-in cameras, games and streaming video, and even hours of MP3 music ... Clearly, the elements of portability, mobility, and instantaneity are driving the public's embrace of the cell phone's increasingly sophisticated, convenient, and user-friendly screen technology. ${ }^{67}$

Individuals who embrace the smartphone culture have committed themselves to carrying iPhones as their chosen medium between the real world and the online world. These highly techno-fluent individuals capture and move digital images online with instant speed. In the case of digital images mimicking analogue however, there is confusion between nostalgia and kitsch. Sherry Turkle in her book Alone Together: Why We Expect More from Technology and Less from Each Other describes these users as: "[t]ethered selves, they try to conjure a future different from the one they see coming by building on a past they never knew." ${ }^{68}$ Nostalgia is a sense of disconnection from the past, and by reinventing the act of snapshot photography, we are recording the present as if it were the past. This reconfiguration disturbs time and space. In a way, we are creating a modern displacement that loses touch with the present. By idealizing, recollecting and re-animating the past, we are creating an uncertain future.

\footnotetext{
${ }^{66}$ Anna Everett, Click This: From Analog Dreams to Digital Realities (Cinema Journal 43.3), 93, accessed November 27, 2010, http://www.jstor.org/stable/3661115.

${ }^{67}$ Everett, Click This, 93-94.

${ }^{68}$ Sherry Turkle, Alone Together: Why We Expect More from Technology and Less from Each Other (New York, Basic Books), 2011, 265.
} 
Nostalgia inspires us: artists use it to rescue old mediums, the entertainment industry uses its warmth and familiarity to draw us to a passive daze, and we are convinced to purchase vintage and retro commodities from clothing to furniture. Boym speaks about the "inculcation of nostalgia" into merchandise such as the iPhone "as a marketing strategy that tricks consumers into missing what they haven't lost" and states that "the alluring object of nostalgia is notoriously elusive. The ambivalent sentiment permeates twentieth-century popular culture, where technological advances and special effects are frequently used to recreate visions of the past." But the nostalgic allure to photography, by making faux 'old' digital photographs will confuse history, reject time, and ignore the future. We embrace technology because it is a wolf in sheep's clothing: devices that are masked with markers of the past. Boym addresses the problem with "prefabricated nostalgia" and states "that it does not help us to deal with the future," explaining that "creative nostalgia reveals the fantasies of the age, and it is in those fantasies and potentialities that the future is born. One is nostalgic not for the past the way it was, but for the past the way it could have been. It is this past perfect that one strives to realize in the future." This commitment we have to the past will fragment our present creating ruins of the present time. Rather than time progressing on its own accord, we expedite time by recording our present with the imitation of the past. The sensation of nostalgia we experience with the mimicry of snapshot photography redefines nostalgia to be not about the past, since it is "both retrospective and prospective. This creates an idealized fantasy of the past that is determined by needs of the present and in turn will be historical consequences with the reality of our future. ${ }^{.69}$ With the 'digital mimicking analogue' look we get from various applications for iPhones for example, the context of the photograph does not match the perceived facsimile of age and deterioration to the print. The aging that comes naturally to analogue photographs: fading, tearing and cracking,

\footnotetext{
${ }^{69}$ This and prior three quotations, Boym, Future of Nostalgia, XVI - 351.
} 
occurs naturally to an analogue photograph. Digital images that apply the 'wear and tear' to the image are a part of the image, or in other words a filter that is flattened within the pixels of the image. It is a false aesthetic, yet at the same time comprises the image. It is a clone from the aged and tarnished analogue print. This may be an alternate aesthetic to today's consumption, but future generations looking back at these images may see the past as false or with confusion.

The contemporary culture in which the digital snapshot mimics 'old' photos is not the same as the culture in which analogue photography reigned. Analogue required commitment and time, and digital embraces the instant and convenience. Digital exposures of pre-determined or premediated image print emulations sanitize the magic of these images taken by smartphones. Well stated in the introduction of American Snapshots: "the sad but inevitable result of our advancing technology has been the declining of fun in actually taking pictures and looking at them." ${ }^{70}$ This discontent, combined with the packaged lifestyle of nostalgia that is being introduced to the smartphone culture offers us a way to produce images that are set apart from the straightforward snapshot photograph. The photo-taker can be 'different' and 'unique' again, just as they where in the analogue era. Manufacturing nostalgia, cleverly packaged and offered as a digital imaging application, remedies the plain snapshot, thereby offering ostensible 'value' and an individualistic quality to an image.

It has now been established that the photographic print is an artifact-document that we value and cherish as a site for nostalgia. I suggest that the word nostos, meaning 'return home,' could also suggest a sense of 'homelessness,' or a place without permanence. Applying this as a metaphor with photography, then analogue photography with its physical prints symbolizes a moment to return to; in other words, the past. This would then render digital images as

\footnotetext{
${ }^{70}$ Jean Shepherd, American Snapshots, authors Ken Graves and Mitchell Payne (California: the Scrimshaw Press), 1977, 6 .
} 
symbolizing a material illusion, a mere representation of a physical photograph, and therefore, there is nothing to return to. Existing only online, digital photography is a virtual reality. The digital photograph, which we believe preserves a sacred time and place, promotes in actuality a false sense of nostalgia. Only analogue photography truly maintains this 'sacred' place because of its physical involvement with the experience. I argue that younger generations, whose first introduction to photography will be via the newest of technologies, like the iPhone, are only now discovering the way things used to be. One can argue that the iPhone application acted as a catalyst for this rediscovery. Most of these young users have not experienced what it is like to take photographs with film, to wait while prints are processed, or to feel them and their flaws in their hands. Today's digitized generation has become attracted to anything that feels authentic, as we love markers of authenticity and elements of realness that we associate with certain aesthetic features. The magic of Lomography for example, is that it is not only a stylized look, its magic lays in its unpredictability - knowing that there are a lot of 'if factors' involved, and that you cant be completely certain how your film will develop. Digital images can be made by anyone, by making a unique picture; however, we can claim it as our own. Re-appropriated signifiers from the past allow us to consider what we do not want to lose and what we do not want to leave behind. We dictate what we want the future to see when they look back to our past by keeping around what we cherish, thus being the basis of communication for our future. As for the Hipstamatic, it gives us digital photography that feels warm and comforting. Digital images can be precise and well balanced, but when you add analogue characteristics, the image somehow feels more intimate. It is necessary to remember that many people grew up looking at photographs in their parents and grandparents albums; it is what we are accustomed to and what connects us to our past. Family photos are evidence of real moments that occurred in time, they 
are permanent objects within the household. In contrast, digital photographs that are in the form of images online are reduced to nothing but a general interest. Viewers online can acknowledge these images as events that have occurred, but this interest is generic and the viewer moves on. Roland Barthes, in Camera Lucida, defines this act as studium: taking in the general qualities of an image. However, when an image is yours, when it is a picture you took of something significant to you, something to which you have a relationship, only then do you attach meaning to it. This engagement with an image is more complicated. The photo takes on a life if its own, evoking feelings and associations deeply embedded in the relationships that one has with the people in the image. ${ }^{71}$ I would suggest that this process wanes when we interact with digital images. Herein lies the claim that the notion of nostalgia is in the images/prints that we grew up with. The pictures that our parents have in albums, have aged, and thus, remind us of our past. Since the inception of the Kodak camera, photographs have been linked to domestic life; they display togetherness, chronicle history and work to mirror and exemplify what domestic life should be like. For most of us, when we look back at our childhoods, they become a series of snapshots.

${ }^{71}$ Barthes, Camera Lucida. 
Tethered selves, they try to conjure a future different from the one they see coming by building on a past they never knew

Sherry Turkle 265

Smartphone devices are sought-after for many reasons. One of the main attractions to acquiring such a phone is the capacity to take higher resolution pictures on a device you will always have with you. This is dominating and continuing to take over the role of snapshot photography by amateurs and professionals alike ${ }^{72}$. Digital imagery did not improve on analogue photography but stopped it in its tracks and replaced it with a lesser version of itself - digital took out analogue's essence and aura, resulting in a cultural craving for the kinds of digital applications that emulate analogue photography. The essence of snapshot photography is about memory, ritual, and nostalgia. But now, as the digital realm is hypermediated, immediate and constant, with socially isolated online photo-posting, snapshot photography is impossible to age: it is left for a future generation to reminisce about the past that once was. In the Arcade Project, Walter Benjamin wrote of the then current but outmoded covered shopping arcades. He read these recently outmoded cultural artifacts as natural-historical ones overturning and satirizing the faith in human history as evolutionary progress. ${ }^{73}$ Benjamin's analysis of the experience of time and our relationship between new and old shows us how we are tied up with aesthetics and embedded in material things. "Yesterday's latest thing is today's trash, and history can be seen not as an onward march but viewed backward, as the production of obsolescence, the piling up detritus." Does going back to shooting by the old methods and producing images, granted digital and fake, remind us of something more real and honest? Analogue images reference more investment and personal connection, but does it clear the clutter of online images, reaching out and grabbing us, and shouting, "look at me, I exist!" For Benjamin, the task would be to sort

\footnotetext{
${ }^{72}$ John Kim, "The Wonderful Hipstamatic Camera," icuriousmedia (2010), accessed July 9, 2010, http://www.icuriousmedia.com/blog/the-wonderful-hipstamatic-camera-1401.php.

${ }^{73}$ Henning, New Lamps for Old, 60 .
} 
through this clutter, "like ragpickers of nineteenth-century Paris [and in this] trash are [these] commodities that have lose their allure [and] can be used to undo the phantasmagoric appearance of modern reality." rate" and warned "that our consciousnesses, individual and collective, were in danger of being overwhelmed, our aesthetic and ethical senses dulled and muddles, be an ever-intensifying blizzard of mechanically produced pictures. How would we be able to sort through them all, to decode their messages and judge their merits?"75 If we don't take a step back and assess the situation, I believe that snapshot photography will become so stagnant and undervalued due to its abundance that this generation will have a hard time sorting through its own history.

Instant-photo devalued photography by making the exchange of images excessively abundant. The smartphone culture's hypermediacy of online image posting has allowed for the diminishment of the family album and the demise of the physical print. Smartphone developers tapped the niche market for nostalgic photography and created the Hipstamatic application to give us images that remind us of a distant history of photography. But, perhaps most importantly, such applications enable us to post these images online in order to convey to our viewers that we are 'alternative', creative and kitschy; that is, we belong to a certain demographic, socioeconomic class and cultural moment, each of which is associated with the nostalgic recapture of analogue photography. These kinds of altered faux-nostalgic images are further devalued, not because of their abundance, but because we don't associate these kitsch images with capturing moments of truth and reality in the way we do with analogue photographic prints. Straight, unaltered digital images are so predominant that we simply take them as they are, dismissed a moment later. Kitschy digital images, altered to elicit nostalgia, are perceived as different from

\footnotetext{
${ }^{74}$ This and prior quotation, Henning, New Lamps for Old, 60.

${ }^{75}$ This and prior quotation, Scott, On (Digital) Photography.
} 
straight images. We do not associate any reality with them due to their falsified nostalgia. Because there is no process involved, what further value can we place on them? One solution is to return to process, producing tactile photographic prints and let them age. It is not that we yearn for a time of the past; rather it is the romantic idea of it. We are already becoming bored with today's photography. Therefore, nostalgia becomes a commodity packaged with the smart devices shoved down our collective throats. Overall, the connection with our images has drastically changed, and we are now asked not to invest or establish an intimate connection to our images because they are no longer 'printed' photographs that become a precious keepsake. Images now, according to Susan Murray, are "simultaneously fleeting." The images we constantly upload online are building blocks for our biographical and social narratives. However, she continues to state that while "these sites build a collection, they also privilege the immediacy of the image and acknowledge the inability of photography to hold onto time even as it provides avenues for nostalgia and memory." ${ }^{, 76}$ Regardless if you are leafing "through old albums or tickle the touch screen you are excavating memory, traveling into the past, whether your destination is the last century or last night," the latest way of viewing images such as the iPhone has become the substitute for the 'family album.' As a tool to build autobiographies, this device is extremely disposable and satisfies its users now and works for the present time, but it will have historical consequences. In the future we will be left wondering why we do not have any mementos from our past. There will be no ecology of images, and as images "make up our ecosystem, they are our native habitat" that make up our realities. As we evolve with images and "learn to negotiate the landscape of digital culture, the history of photography can provide a compass and a map. The camera, the darkroom, the museum and archive all exist in the same place." Being everywhere and nowhere at the same time online in social networks and on our cellphones,

\footnotetext{
${ }^{76}$ This and prior two quotations, Murray, Digital Images, 161.
} 
"every one of us commands a factory and a storehouse of images, vessels of information and nostalgia, desire and curiosity." Each of us spends our time browsing through it all to search "out shards of memory and intimations of mortality." the documents our parents kept in photo albums and drawers, have survived and exist. I can hardly believe that my children or even grandchildren will get a CD of my Facebook profile. Nostalgia must be embodied in the material form of photographs.

${ }^{77}$ This and prior four quotations, Scott, On (Digital) Photography. 


\section{AFTERWORD}

Embodied Nostalgia is a personal, methodological investigation into why and how nostalgia has become pervasive in our digital culture. This book thus embodies my desire to create a document that contributes to this trend while attempting to understand it. This book encapsulates research and opinions, which come together to formulate an answer to the queries laid out from the introduction onwards. The photographic body of work produced in conjunction with this thesis is a combination of analogue and digital photography. The pages within this thesis were created to resemble a vintage body of work, bearing witness to the physical results of the passage of time. A classic typewriter font was incorporated to allow the reader to identify visually with a past era. As part of this process, I requested my supervisors to do their last edits on one master copy of my thesis. Their handwriting and thoughts are their own, and have been maintained to connote authenticity. This serves a twofold purpose; the handwriting and intentional distressing of the pages create a one of a kind object, which reinforces the topic of the project. Secondly, my supervisors' thoughts and ideas are kept in view rather than lost within the digital alteration of a word processed document. This was meant to allow for contemplation of the suggestions and alterations, which were provided supposedly for my own eyes only. This act of incorporating normally private information confronts the lost perception of the work behind the dissemination of information. Each individual page was scanned and the scanned pages were bound into a book. The document is my thesis; at the time I reinforce the visual aesthetics related to nostalgia in documents and images.

I photographed the series of images during the Spring of 2011. The subjects of the images are all people who routinely attempt to create and maintain a 'classic' or 'vintage' appearance. The singular direction concerning the clothing used by each subject was to simply look 'timeless'. This direction was taken and executed through each sitter's consideration and 
personal understanding. The analogue and digital montage of each image resembles the aesthetic and visual theory of the moving image, maintaining a form of narrative within each images. This enables the viewer to elicit memories from the past, reminiscent of flipping through family albums.

The sitter is meant to be a vessel for the audience's memories. She is your Sister, Mother, or Aunt. He is your best friend, Brother, or childhood hero. She is your past lover and he is your Mother's first boyfriend. They are anyone who is conjured from your memory. Alive or imagined, they are constructions that evoke a time past. They symbolize instants of the past and the moments that we cherished in our minds. They are familiar and welcoming; they are the key to unlocking that feeling you get when you flip through your Grandmother's family album.

Arriving at prints that appear as vintage analogue photographs, similar to one's parents' albums, took some trial and error. I actually began the project by re-photographing found photographs of anonymous strangers bought at an antique market, but I realized it was important to photograph the present in order to represent my own relation to nostalgia. In the end, I used my old Canon AEI full manual camera and with a novelty lens that bends and shifts, allowed me to create and control soft and blurred peripheral areas of the frame. This particular lens, called Lensbaby, is manufactured for digital single lens reflex (DSLR) cameras to create analoguelooking images with a digital camera. But using a DSLR with this lens results in digital images lacking grain and warmth. This particular loss in the photograph prompted my use of film as opposed to digital photographs. As the lens is made for digital cameras, I could not simply mount the lens to the analogue camera. I was unable to locate the proper converter mount, and I adapted the mounting system by adhering the lens onto the body of my camera. With film from the Lomography store I was able to produce the images compiled for these pages. I purchased 
Lomography 35mm Redscale XR 50-200 ISO film. The colour tones vary according to the ISO exposure settings of my manual camera; this film has cooler tones when shot at lower ISO, and thus gives the retro feel I sought. At high ISO, the colors show more intense red and orange tones. Depending on the weather and time of day, I shot mostly around 50 ISO. I had each roll processed and printed into $4 \times 6$ prints. Then I took selected prints and back lit each, thus exposing the back of the print and merging it with the front. The re-photographed results enable the viewer to be reminded of the tactility of the print. After the digital image was created, I used Adobe Illustrator to sequence and overlap each image with different transparency settings, causing one image to blend into the next and reinforcing the intentional narrative feeling.

The physical process involved with this project was vital to my personal sense of truth in the execution of the series: going to purchase the film; loading my camera; shooting; winding the film; dropping the film off to the developers; anticipating the result of the shoot with excitement and uncertainty if the images will resemble exactly what I had hoped; picking the images up and paying for them; shuffling through the $4 \times 6$ shots and choosing the right prints almost instantaneously; and finally arriving home and organizing them. This entire ritual is symbolic of my thesis. The end result is this book in your hands, where my words, ideas, images and research come together to reveal my vision of nostalgia. 